\title{
Can Sustainability Co-exist with Resilience?
}

\section{Priyan Dias}

Emeritus Professor, Department of Civil Engineering, University of Moratuwa, Sri Lanka

ABSTRACT
Although sustainability and resilience are widely seen as two major
complementary global goals, we question whether the quest for resilience
is in fact inimical to sustainability. We do so by viewing development (both
human and physical) on the one hand, and durability or longevity on the
other as proxies for resilience. We argue that flourishing may need to
be tempered with deprivation in order for humans to survive. However,
drawing on the structural mechanics roots of the term "resilience", we
demonstrate how the concept of "ductility" could provide a model for
resilience to co-exist with sustainability. Ductility is analogous to dealing
with unforeseen stress through a change in behavior - typically the
acceptance of a temporary loss of service or even permanent change in
state, rather than the provision of spare capacity.

\section{KEYWORDS:}

Sustainability, resilience, ductility, development, scarcity, durability

Suggested Citation: Dias, P. (2021). Can Sustainability Co-exist with Resilience? University of Colombo Review (New Series III), 2(2), 122 - 132.

(C) 2021 The Authors. This work is licenced under a Creative Commons Attribution 4.0 International Licence which permits unrestricted use, distribution, and reproduction in any medium, provided the original work is properly cited. 


\section{Introduction}

Sustainability and resilience are two of the most commonly used words which enjoy global currency today. While the concept of resilience has early 19th Century structural mechanics roots (Dias \& Viswakula, 2020), it has been broadened to encompass a range of domains, for example, technological (or more broadly infrastructural), environmental, economic, societal, and geopolitical systems, as spelt out in the World Economic Forum's (2013) Global Risks 2013 report. Resilience can be defined as the ability of a system to withstand and absorb stress, without losing its equilibrium, which could include a migration to a new equilibrium. Resilience has been characterized as having three components, namely robustness, redundancy, and ductility (Dias, 2015; Dias \& Viswakula, 2020). Robustness involves good distribution of resources and sharing of stress. Redundancy implies that alternative measures or avenues are available when the system is subject to stress. Ductility, which is conceptually similar to the idea of resourcefulness as defined by the World Economic Forum (2013), captures the structural engineering concept that a system will change its behavior in order to sustain stress, albeit with some permanent deformation, but without fracturing.

The concept of sustainability has been traced to the 1960s (Ricketts, 2010). While it too applies to many world sub-systems, such as spelt out above, its primary focus is on the environment. There have, of course, been many earlier well-known proponents of simple living and environmental conservation, such as Mahatma Gandhi in the Eastern world and Henry David Thoreau in the West. Many ancient religious traditions can also be viewed as promoting a symbiosis with nature, as captured in Weeramantry's (2009) Tread Lightly on the Earth. In some ways, the concept of sustainability can be seen as a pushback against that of development. The notion of development is a post-World War 2 phenomenon, which largely divided the world into "developed" and "developing" nations; and gave rise to various global financial institutions such as the World Bank (Lepenies, 2008), purportedly to help the latter to achieve the economic status of the former. However, the development in rich countries brought with it issues of environmental degradation (Carson, 1962) and resource depletion (Meadows et al., 1972). It is this background that resulted in the Brundtland Report defining sustainable development as "development that meets the needs of the present without compromising the ability of future generations to meet their own needs" (WCED, 1987, p. 43), with development here referring primarily to physical development. This brings in the notion of inter-generational justice too. Note the well-known Native American quote: "Treat the Earth well, it was not given to you by your parents, it was loaned to you by your children". Meanwhile, the United Nations' (1990) Human Development Report introduced the concept of human development, described in more detail in the next section.

The intention of this article is to explore the nexus between sustainability and resilience. Its focus is physical infrastructure, which is another globally important entity, given that large parts of the developing world are acquiring it. At the same time, similarly large parts of the developed world are struggling to maintain or replace their infrastructure, since it is in the post-World War 2 era that much of it was put in place, and a large proportion 
of it is now over 50 years old. In the context of physical infrastructure, sustainability has been viewed as a subset of resilience (Blockley et al., 2012) - in other words, for something to be sustainable, it has first to be resilient. Sustainability is primarily seen here as reducing energy inputs to, and carbon emissions from the built environment, whether embedded in its materials or consumed during its operation (Dias \& Pooliyadda, 2004). The construction industry is widely acknowledged as a major player in both generating environmental stress, as well as having the potential to reduce it. Estimates indicate that the industry contributes to $23 \%$ of air pollution, $50 \%$ of climatic change, $40 \%$ of drinking water pollution, and $50 \%$ of landfill wastes (GoContractor, 2017). Given these statistics, resilience - i.e. ensuring infrastructure longevity - is considered a pre-requisite for sustainability as premature reconstruction will further damage the environment. Such resilience needs to be displayed even in the face of increased natural disasters (brought about by climate change), and increased human impacts, inclusive of war and conflict (caused by complex sociopolitical factors). However, one of the main questions we raise is whether resilience is in fact inimical to sustainability, rather than being a pre-requisite for it. We also explore the various dimensions of resilience to discover whether any of them are more consistent with sustainability.

\section{Is Sustainable Development an Oxymoron?}

We start with the question as to whether development can co-exist with sustainability. Where sustainability is concerned, we use the widely accepted idea of an ecological footprint (Rees \& Wackernagel, 1996), which captures both the demand and supply side of nature. It measures the ecological assets that a given population (or product) requires to produce the natural resources it consumes and to absorb its waste, especially carbon emissions. What we will do is to explore the performance of Asian countries with respect to ecological footprint per capita (EFpc) in a given year. The footprint has units of global hectares (Gha). The data on EFpc has been obtained from the Global Footprint Network's The Ecological Wealth of Nations, with data from 2013, and used by Kaklauskas et al. (2020). The Environmental Performance Index (EPI) can be considered an alternative to the ecological footprint and is based on 32 performance indicators under the following 11 issue categories: air quality, sanitation and drinking water, heavy metals, waste management, biodiversity and habitat, ecosystem services, fisheries, climate change, pollution emissions, agriculture, and water resources (Wendling et al., 2020). It should be noted that sustainability demands a reduced $E F p c$ but an increased EPI. We use EFpc in what follows because it is a directly tangible measure rather than a derived index.

Where development is concerned, we focus on human development rather than physical development because the former could be considered more acceptable for sustainability compared to the latter - as already noted in relation to the environmental impacts of the construction industry described in the introduction of this article. The Human Development Index (HDI) is a composite index of life expectancy, education, and per capita income indicators; the data is from 2015 (UNDP, 2015), and also used by Kaklauskas et al. (2020). Note that we are here considering development to be a proxy for resilience (Kimhi et al., 2018). 
We now re-present in Figure 1 a graph based on Kaklauskas et al. (2020) but introducing a polynomial to capture the relationship between variables. While the 4 th order polynomial may constitute overfitting to a degree, it captures the downturn of the curve at the upper end of the data. The first thing to notice in the curve is that EFpc generally increases with $H D I$. Although the curve is merely a correlation rather than a causal relationship, it appears that an increase in $H D I$ (aspired to by all countries) would be attended by an increase in EFpc as well - which would compromise global sustainability.

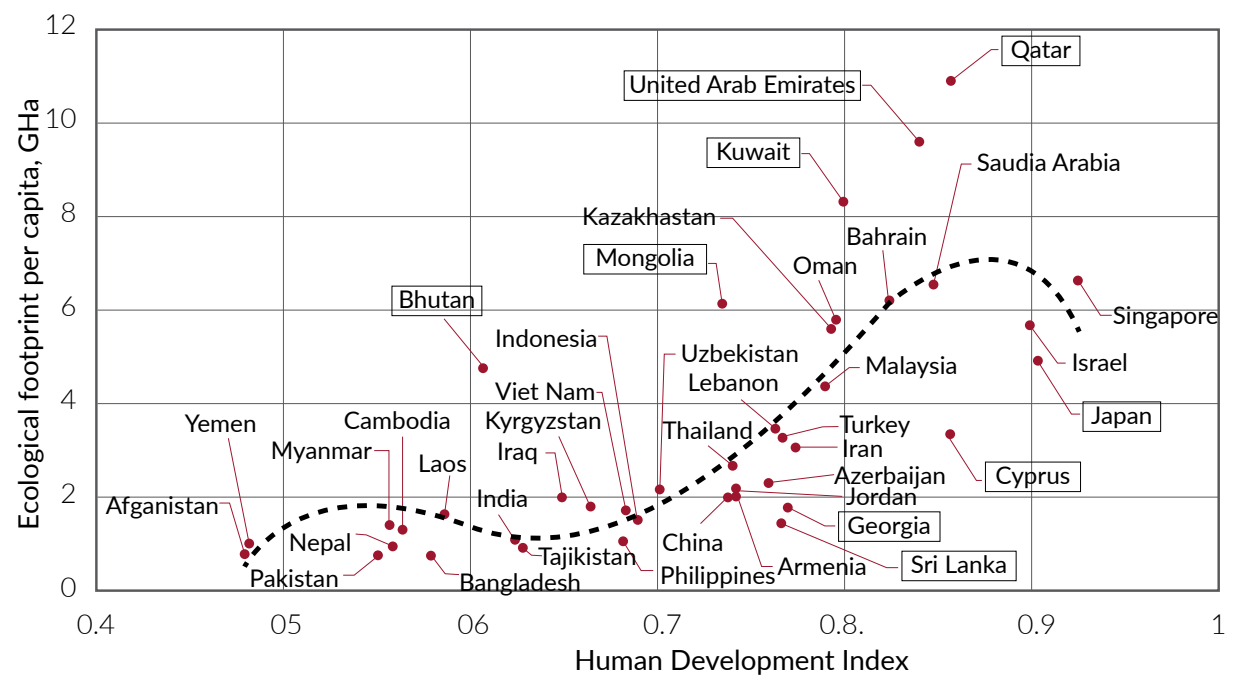

Figure 1

EFpc vs. HDI for Asian countries (based on Kaklauskas et al., 2020)

It is instructive to look at the nine countries that are the most distant from the curve in Figure 1, outlined in text boxes. Note that countries below the curve can be seen as achieving their $H D I$ levels with corresponding lower EFpc values than reflected by the trend. We can also consider these countries with respect to the median values of $H D I$ (which is 0.741) and EFpc (which is $2.15 \mathrm{Gha}$ ). Qatar, United Arab Emirates (UAE) and Kuwait, all West Asian nations that produce oil, are above the curve and have both EFpc and HDI above their medians. Japan and Cyprus are below the curve and have a lower EFpc than the three countries above, but are, nevertheless, above the median, and also have an HDI above the median. Bhutan and Mongolia which are sparsely populated countries and above the curve have EFpc above the median, but $H D I$ below its median. Georgia and Sri Lanka on the other hand are below the curve, have EFpc below the median and HDI above it - this constitutes the best performance, because a relatively high level of (human) development has been achieved with low environmental impact.

The other feature in the Figure 1 curve is the downturn referred to above. Countries that constitute this downturn are Singapore, Israel, and Japan, all with very high HDI. The work of Tarte (2009) suggests that $E F p c$ will decrease with time for such countries. Hence, it could be argued that increases in $H D I$ could actually be experienced with reducing $E F p c$, but beyond a certain level of $H D I$, by which time EFpc would be rather high. So, although 
this reducing trend of $E F p c$ with $H D I$ is cause for some hope where human life on the planet is concerned, it should be noted that the EFpc levels at which this might happen (see Figure 1) are much higher than the "fair earth" share of 1.7 Gha per capita (Moore \& Rees, 2013). The above analysis therefore does seem to confirm that sustainable development is an oxymoron!

\section{Does Resilience Help or Hurt?}

In the previous section, we presented development as a proxy for resilience. Here we consider durability or longevity as such a proxy. As mentioned in the introduction, one of the biggest problems faced by infrastructure in the developed world is its deterioration, especially through steel corrosion in structures made of reinforced concrete, which is the most commonly used structural material worldwide. This has given rise to a focus on concrete durability. Typical reinforced concrete structures are supposed to have a relatively maintenance-free lifespan of 50 years; but this can reduce to 20-30 years in aggressive, chloride rich marine environments (Mehta, 2001) - and a disproportionate amount of the world's physical development has taken place along coasts. Design codes now give specifications for designing structures up to 100 years (BS 8500: Part 1: 2016). This of course requires more cement, which is one of the most energy and carbon intensive building materials. It could be argued, though, that the added costs (both financial and ecological) are justified, because repair and rehabilitation of existing non-durable structures are very expensive.

However, especially with increasing migration to cities, it appears that building life span is curtailed not by poor durability, but by demolition, especially in the developing world, in order to make way for changing cityscapes. For example, $85 \%$ of buildings demolished in Chongqing, China were below the typical design life of 50 years, with $46 \%$ below 30 years (Shen et al., 2013). The average lifespan was only 35.9 years (with a minimum of 8 and maximum of 80 years). So in this case, the lifespan of building infrastructure is reduced not because of poor durability, but rather, by urban renewal. This phenomenon perhaps demands equal attention to that given to durability. Even in Japan, which is a developed country, the average lifespan of a residential building is reportedly only 25 years, and reducing since World War 2 (Wuyts et al., 2019).

The construction industry has indeed made some responses (Mehta, 2001). First, the increased durability required has largely been achieved, not so much by greater consumption of cement, but by the partial substitution of cement with industrial waste products such as fly ash (from coal power generation) and blastfurnace slag (from the steel industry). This is quite a remarkable and synergistic achievement which has not been adequately appreciated, even within the construction community in some parts of the world. The industries referred to are themselves highly polluting ones, however; but if agricultural waste (e.g. rice husk ash) can be made as effective as industrial waste, the construction industry may be able to improve its contribution to sustainability. Second, the response to demolition (premature or otherwise) has been to recycle construction waste as aggregates (i.e. the inert matrix) for concrete. This response is, however, relatively new and not very widespread. It must be noted 
that the supply of natural aggregate itself is becoming a challenge, due to overexploitation (e.g. excessive river sand mining).

There is also now increasing awareness of sustainability in the construction industry, with various rating systems in place to assess how "green" a building is (Chandratilake \& Dias, 2013); and the achievement of high sustainability ratings is also considered good for business in the corporate world. However, there are critiques of such systems too, since they are essentially technological in nature, and could even increase consumption, rather than encouraging a return to simpler lifestyles, reduced resource use, and practices that encourage regeneration of resources - see Hahn (2008), who reports a fourfold increase in per-occupant volume in US houses over 50 years.

Just as human needs have increased with the years, so have human populations and their lifespans. One of the novelist Dan Brown's (2013) protagonists in his novel Inferno seeks to cause a plague that will make one third of the world's population infertile on a random basis. The novel is probably a response to the world's overpopulation, portrayed by a doomsday scenario (Carter, 1983). Malthusian catastrophes for checking overpopulation also appear to have been averted by humans, due to their increased resilience against both disease and disaster. (Neo-Malthusians, however, correctly advocate for reducing poverty as a strategy for the population explosion). The question is whether currently increasing and resilient populations will continue to be able to overcome resource limitations into the future. Elon Musk, one of the world's foremost entrepreneurs, while seeking massive conversions from fossil fuel based power to solar power, is also seriously contemplating the colonization of Mars (Vance, 2015).

Meanwhile, there does appear to be some return to simplicity in the construction industry, for example through the use of timber and earth-based materials in construction, recognized as materials that are closer to nature and having a natural death (Pone \& Pone, 2017). The above authors quote from Andrej Tarkovskij's 1979 film Stalker: “when man is born, he is weak and ductile. When he dies, he is strong and stiff. Just like a tree: while growing it is tender and flexible, yet when it is hard and dry, it dies"; and call for soft infrastructure that is more attuned to the biological rhythms of the earth, inclusive of death. The reference to the tree is instructive. It raises the question as to whether being (conventionally) hard is better than being flexible - we come to this in the next section too, where "ductility" is presented as an aspect of resilience that could indeed be compatible with sustainability. Robert Harris, in his novel Pompeii, has the following reflection made by the main protagonist in the story, namely a Roman hydraulic engineer of antiquity: "he thought how quickly Nature seized back what she had yielded - brickwork was crumbled by rain and frost, roads were buried under green drifts of weeds, aqueducts were clogged by the very water they were built to carry. Civilisation was a relentless war which Man was doomed to lose eventually" (2004, p. 233; see also Dias, 2010). Is resilience in the form of durability, then, an elusive goal in any case?

Thoreau (1854) saw a dwelling shelter as an outer layer of clothing and cautioned against the perils of economic loss associated with extravagant housing, whether rented or owned. Where Japanese residential buildings are concerned, the question is raised as 
to whether ending rather than extending their lifespan is the better approach (Wuyts et al., 2019). Meanwhile, the growing appreciation of a circular economy also endorses the above sentiments, promoting as it does reducing, reusing, and recycling. One of the concepts presented by Zolli and Healy (2012) in their book Resilience, is that pervasive phenomena, whether tuberculosis or terror networks, scale down as well as up in their survival processes. Moreover, Amartya Sen (2013) suggests that scarcity, or an economy of subsistence, would be the only real sustainability option; and in some ways scarcity, within limits, can be argued as promoting human resilience as well.

So, inasmuch as the concept of resilience is associated with ideas such as durability, longevity, and hardness, it may be at variance with sustainability. There are, however, some threads of thought that want to align it with ideas such as softness, flexibility, and circularity, which may be more compatible with sustainability. We look at one such aspect of infrastructure resilience next.

\section{Resilience through Ductility: One Way Forward?}

We noted in the introduction that resilience could be seen as comprising robustness, redundancy, and ductility, if a structural mechanics analogy were to be used (Dias \& Viswakula, 2020). Of these, robustness signifies good distribution of resources and sharing of stress. It could, however, also contribute to the idea of durability, longevity, and hardness, which could be inimical to sustainability. Redundancy, which implies the existence of more than what is required, will, once again, consume resources, although such spare capacity seems necessary to deal with stress over and above the normal. Ductility on the other hand is an interesting concept. A ductile material, under stress, transitions from elastic to plastic behavior. A material is able to absorb much more (disruptive) energy in a plastic mode than in an elastic one. At the same time, the cross-sectional area of a structural element that is intended to behave in a plastic manner will be much less than that of an element expected to behave only elastically. The plastic behavior will, of course, cause some plastic deformation, but without fracture. These are very specific structural mechanics concepts (Dias, 2015), but they can be used analogically to explore the resilience of other systems too (Dias \& Viswakula, 2020).

One of the key findings of such analogical exploration is that infrastructural "ductility" can be traded off with redundancy (Dias \& Viswakula, 2020). We can see physical manifestations of this concept too. For example, the Storm-water Management and Road Tunnel (SMART) in Kuala Lumpur caters for road traffic as well as stormwater drainage below it. When runoff is excessive, however, perhaps only once in several years, the road traffic is curtailed and the entire tunnel only discharges the storm-water (Navaratnarajah, 2016). Here the infrastructure asset, i.e., the SMART tunnel, is able to perform well albeit differently under duress, i.e., it is "ductile". This obviates the necessity to invest in additional runoff capacity; i.e., it reduces the need for redundancy. There is, however, some loss of function during the occasional rainwater stress as no traffic can use the tunnel. 
Another example of such ductility is the Watersquares of Rotterdam. These are public spaces that perform a vital social function in a city. However, during heavy flooding, they are allowed to fill with water and hence temporarily unavailable for residents. A final example is the morning rush hour traffic control in the city of Dehiwala, the suburb immediately south of Sri Lanka's capital city of Colombo. The main arterial road through Dehiwala is the Galle Road, which has two lanes each in north and south bound directions. During the morning rush hour into Colombo one of the southbound lanes is converted to a northbound one. This causes loss of service for southbound traffic, but increases the overall level of service, especially for the vast majority of northbound commuters. The system can be thought of as behaving in a ductile manner - i.e., changing its behavior and/or state to accommodate the additional traffic stress. As one enters Colombo, however, there are two parallel north-south roads (redundancy), so the artificial traffic control is not required. Thus, ductility can be traded off with redundancy, but when opting for ductility, only one road rather than two is required - see Figure 2.

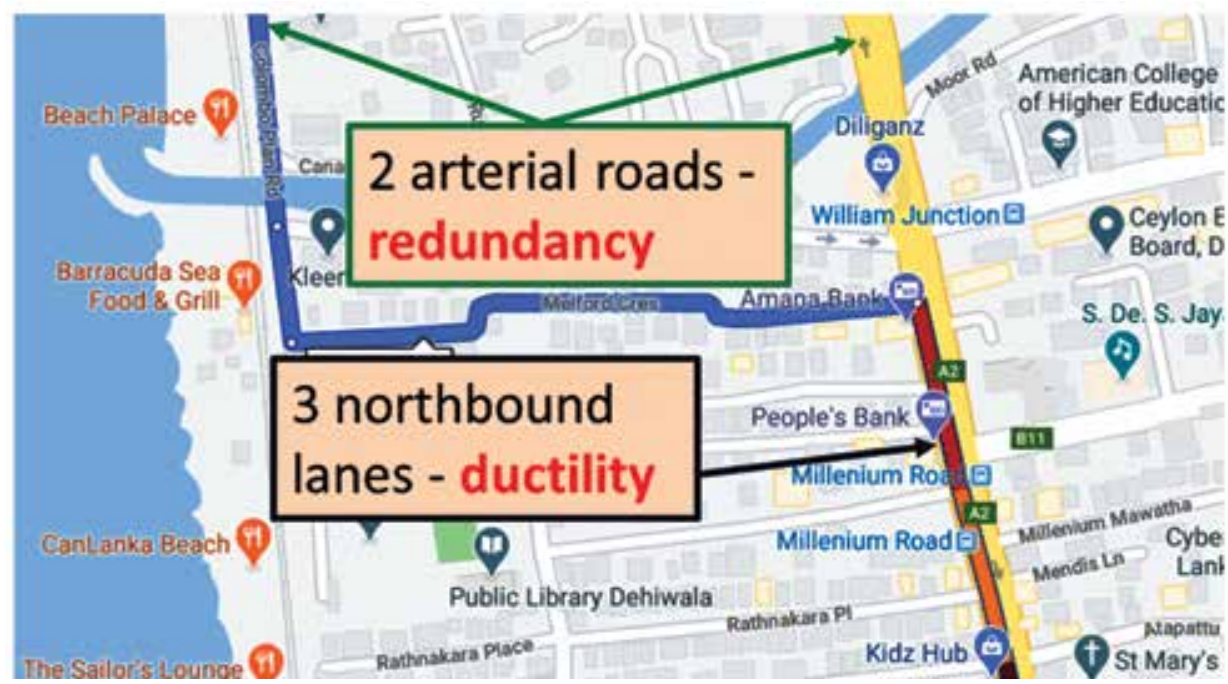

Figure 2

Trade-off between ductility and redundancy in rush hour traffic control

\section{Conclusion}

We have, in this article, considered the nexus between sustainability and resilience. Sustainability is a universally sought goal - consider for example the widely accepted Sustainable Development Goals set out by the United Nations. However, they appear to be elusive. Notwithstanding the Sendai Framework for Disaster Risk Reduction (UNDRR, 2015), we have somewhat provocatively questioned whether it is the parallel pursuit for resilience that is contributing towards making them elusive. In order to raise this provocation, we have defined resilience in two ways - e.g., as development (both physical and human), and also as characterized by durability or longevity. Such definitions of resilience appear to 
place it at variance with sustainability. However, we ended by demonstrating that resilient infrastructure can be developed with the analogical property of ductility borrowed from structural mechanics, with its capacity to change behavior under periodic increases in stress, instead of relying on redundancy. This does indeed save scarce resources, although associated with a certain loss of service during periods of distress. This infrastructure based model could conceivably be extended to other areas where the goals of sustainability are in conflict with those of resilience. It appears that the "good life" (resilience) has to be tempered with scarcity (ductility), in order for humanity to survive (sustainability).

\section{References}

Blockley, D., Agarwal, J., \& Godfrey, P. (2012). Infrastructure resilience for high-impact low-chance risks. ICE Proceedings on Civil Engineering Special Issue, 165(6) (CE6), 13-19. https://doi. org/10.1680/cien.11.00046

Brown, D. (2013). Inferno. Doubleday.

BS 8500: Part 1: 2016. Concrete - Complementary British Standard to BS EN 206 Part 1: Method of specifying and guidance for the specifier. British Standards Institution.

Carson, R. (1962). Silent spring. Ballantine.

Carter, B. (1983). The anthropic principle and its implications for biological evolution. Philosophical Transactions of the Royal Society of London. Series A, Mathematical and Physical Sciences, 310(1512), 347-363. https://doi.org/10.1098/rsta.1983.0096

Chandratilake, S. R., \& Dias, W. P. S. (2013). Sustainability rating systems for buildings: Comparisons and correlations. Energy, 59, 22-28. https://doi.org/10.1016/j.energy.2013.07.026

Dias, P. (2010). Pompeii by Robert Harris: An engineering reading. ICE Proceedings on Engineering History and Heritage, 163(4), 255-260. https://doi.org/10.1680/ehah.2010.163.4.255

Dias, P. (2015). Is toughness a better metaphor than resilience? Civil Engineering \& Environmental Systems, 32(1-2), 68-76. https://doi.org/10.1080/10286608.2015.1016922

Dias, P., \& Viswakula, S. (2020). Structural mechanics analogies for a resilience audit and index. 2020 Moratuwa Engineering Research Conference (MERCon) (pp. 66-71). IEEE. https://doi. org/10.1109/MERCon50084.2020.9185398

Dias, W. P. S., \& Pooliyadda, S. P. (2004). Quality based energy contents and carbon coefficients for building materials: A systems approach. Energy, 29(4), 561-580. https://doi.org/10.1016/j. energy.2003.10.001

GoContractor. (2017, June 21). How does construction impact the environment? https://gocontractor. $\mathrm{com} / \mathrm{blog} / \mathrm{how}$-does-construction-impact-the-environment/

Hahn, T. J. (2008). Research and solutions: LEED-ing away from sustainability: Toward a green building system using Nature's design. Sustainability, 1(3), 196-201. https://doi.org/10.1089/ SUS.2008.9959 
Harris, R. (2004). Pompeii. Arrow Books.

Kaklauskas, A., Dias, W. P. S., Binkyte-Veliene, A., Abraham, A., Ubarte, I., Randil, O. P. C., Siriwardana, C. S., Lill, I., Milevicius, V., \& Podviezko, A., \& Puust, R. (2020). Are environmental sustainability and happiness the keys to prosperity in Asian nations? Ecological Indicators, 119, 106562. https://doi.org/10.1016/j.ecolind.2020.106562

Kimhi, S., Parmak, M., Boon, H., Sapountzaki, K., Groh, A., \& Ryan, S. (2018). Community and national resilience and quality of life: A preliminary cross-cultural study. American International Journal of Social Science, 7(1), 1-11.

Lepenies, P. H. (2008). An inquiry into the roots of the modern concept of development. Contributions to the History of Concepts, 4(2), 202-225. https://doi.org/10.1163/187465608X363472

Meadows, D. H., Randers, J., \& Meadows, D. L. (1972). The limits to growth: A report for the Club of Rome's project on the predicament of mankind. Universe Books.

Mehta, P. K. (2001). Reducing the environmental impact of concrete. Concrete International, 23(10), $61-66$.

Moore, J., \& Rees, W. E. (2013). “Getting to one-planet living”. Is sustainability possible? (pp. 39-50). The Worldwatch Institute. Island Press.

Navaratnarajah. K. (2016). Engineering towards a resilient world - managing client expectations. The Structural Engineer, 94(4), 10-15.

Pone, M., \& Pone, S. (2017). Post-formed timber gridshell and systems of "soft infrastructure". Proceedings of IASS Annual Symposia, IASS 2017 Hamburg Symposium: Timber Gridshells and Bio-based Structures, pp. 1-8. International Association for Shell and Spatial Structures.

Rees, W., \& Wackernagel, M. (1996). Urban ecological footprints: Why cities cannot be sustainableand why they are a key to sustainability. Environmental Impact Assessment Review, 16(4-6), 223-248. https://doi.org/10.1016/S0195-9255(96)00022-4

Ricketts, G. M. (2010). The roots of sustainability. Academic Questions, 23, 20-53.

Sen, A. (2013). The ends and means of sustainability. Journal of Human Development and Capabilities, 14(1), 6-20. https://doi.org/10.1080/19452829.2012.747492

Shen, L-Y., Yuan, H., \& Kong, X. (2013). Paradoxical phenomenon in urban renewal practices: Promotion of sustainable construction versus buildings' short lifespan. International Journal of Strategic Property Management, 17(4),377-389. https://doi.org/10.3846/1648715X.2013.849301

Tarte, A. B. (2009). Identifying indicators of sustainable development using the global sustainability quadrant approach [Unpublished master's thesis]. Michigan Technological University.

Thoreau, H. D. (1854). Walden. Ticknor and Fields.

United Nations Development Programme (UNDP). (1990). Human development report, 1990.

United Nations Development Programme (UNDP). (2015). Human development indicators by country 2015. 
United Nations Office for Disaster Risk Reduction (UNDRR). (2015). The Sendai Framework for Disaster Risk Reduction 2015-2030.

Vance, A. (2015). Elon Musk: Tesla, SpaceX, and the quest for a fantastic future. Ecco.

Weeramantry, C. G. (2009). Tread lightly on the earth: Religion, the environment and the human future. Stamford Lake.

Wendling, Z. A., Emerson, J. W., de Sherbinin, A., Esty, D. C., et al. (2020). 2020 Environmental Performance Index. Yale Center for Environmental Law \& Policy.

World Commission on Environment and Development (WCED). (1987). Our common future. Oxford University Press.

World Economic Forum. (2013). Global risks 2013 (8th ed.).

Wuyts, W., Miatto, A., Sedlitzky, R., \& Tanikawa, H. (2019). Extending or ending the life of residential buildings in Japan: A social circular economy approach to the problem of shortlived constructions. Journal of Cleaner Production, 231, 660-670. https://doi.org/10.1016/j. jclepro.2019.05.258

Zolli, A., \& Healy, A. M. (2012). Resilience: Why things bounce back. Simon \& Schuster. 